\title{
Use of Social Networking Sites for Recruiting and Selecting in the Hiring Process
}

\author{
Marysol Villeda ${ }^{1} \&$ Randy McCamey ${ }^{2}$ \\ ${ }^{1}$ College of Business Administration, Tarleton State University, USA \\ ${ }^{2}$ Dr., College of Business Administration, Tarleton State University, USA \\ Correspondence: Marysol Villeda, College of Business Administration, Tarleton State University, 1333 West \\ Washington Street, Stephenville, TX 76402, USA.
}

Received: December 24, 2018

Accepted: January 30, 2019

Online Published: February 11, 2019

doi:10.5539/ibr.v12n3p66

URL: https://doi.org/10.5539/ibr.v12n3p66

\begin{abstract}
Business' departments are already taking advantage of the convenience of technology, while global competition continues to demand creativity in terms of how employers acquire human capital. Thus leading to the question, how can employers take full advantage of technology in the hiring process? For instance, social networking sites (SNS) are being explored as an additional tool for recruiting and selecting the best-suited employees. Even though all types of businesses are taking the initiative to attempt the integration of SNS into their hiring process, many may still lack understanding on how candidate experience influences employer brand image, in addition to its actual benefits and risks. Through the analysis of peer-reviewed journals and other reliable sources concerning the effect of SNS on recruiting and selecting employees, we have found many benefits in the recruiting process, while SNS used in the selecting process could bring further challenges to employers. For instance, lower cost and time per hired employee, ability to reach a high number of possible applicant especially younger generations, ability to attract passive job applicants, and the inclusion of a supplementary method for employee performance predictions are the most important benefits SNS presents to the overall hiring process. On the contrary, legal issues, inability to attract a diverse pool of candidates, the lack of reliability and validity of such platforms, and the overall accuracy of information obtained are risks and pitfalls of the combination of SNS and the hiring process. After examination, we conclude that SNS should be used in recruiting and selecting of employees, but employers should not solely rely on such platforms. Employers greatly benefit from the unbiased information concerning SNS, but as time progresses and processes evolve, further research is always needed in order to reinforce or challenge earlier findings.
\end{abstract}

Keywords: recruiting, screening, selecting, social networking sites

\section{Introduction}

The social media trend has caused such a hype that even organizations want to get onboard and utilize them as a business tool. Stories of how the institution that play a significant role in society are initiating the process of integrating social media sites into their hiring process are becoming more common. One specific example of this practice was demonstrated by the Dallas Texas Police Department. In an interview with Senior Corporal Dane White (April 2018), a recruiter for the Dallas PD told the authors about his use of social media for recruiting. Officer White stated that the use of social media for recruiting is essential to reach millennials since other methods such as radio and television no longer reach the desired audience. The main social media sites used by the Dallas PD are Facebook, with the specific account Dallas Police Department Recruiting that as of 2018 had more than 12,000 followers; and Twitter (@DPRecruting) with more than 1,400 followers. Dallas PD was using \#DPrecruiting, and the new campaign \#30Days30Reason as part of a campaign to hire 250 additional police officers. This campaign consisted of informing possible job applicants of the Dallas PD culture, incentivizing candidates to take advantage of DM's (direct messages), and tags to reach recruiters (Recruiting DP, 2018). In addition, the Dallas PD used social platforms to inform candidates of their specific recruiting location. Officer White stated that social media had allowed Dallas PD to reach out to a higher number of candidates and specifically target millennials (White, April 2018). This is just one of the many cases of a business taking advantage of technology and social media. 


\section{Theoretical Approach/Analysis}

The area of human resource management (HRM) has roots in the 1800s as a result of Robert Owens' development of "welfare to work" which sought to improve the working environment for employees (Deadrick \& Stone, 2014). From the beginning of the 1900s to 1970s, HRM became broader encompassing the era of Fredrick Taylor that strived to increase production efficiency. During this period, the field of HRM was seen as relevant to relations movement. For instance, due to oppressive management practices in the United States, major acts were enacted. The Wagner Act of 1935 gave employees the right to unionize; the Taft Hartley Act was later passed to provide a balance between union and management power (Deadrick \& Stone, 2014). The early theory behind HRM was mainly concerned with the welfare, safety, and psychology movements (Kaufman, 2014).

However HRM is more than theories of motivations and relations, in present time, it is viewed and accepted as a strategy that enhances the effectiveness of overall business. Human resources management is now defined as policies, processes, and systems concerning the incorporation of employee performance to the overall company strategy (Noe, Hollenbeck, Gerhart, \& Wright, 2014). Subsections or departments included are recruiting, training and development, performance appraisal, reward systems, and compensation, among others. The practice of HRM must consist of staffing and hiring which begins with recruiting. Recruiting objectives range from the filling a number of vacant positions, type of candidates sought, and time frame to fill positions (Breaugh, 2008). Recruiting strategy consists of whom, where, and how to recruit. The following steps include the actual recruitment activities and the results in comparison to the objectives (Breaugh, 2008).

\subsection{Evolution of Recruiting}

As the overall HRM has expanded to include more extents and topics, the specific area of recruiting and its following procedures of screening and selecting have also evolved. For instance, from the 1950s to 1980s around $75 \%$ of candidates were reached through newspaper advertisements (Hebberd, 2017). By the end of the 1900s several web-based recruiting sites were launched including careerbuiler.com, hotjobs.com, and monster.com; thus, opening the path for online job seekers which increased from 6\% in 2002 to $96 \%$ in 2006 (Hebberd, 2017). The modern extent of recruiting mainly consists of the internet, which as of 2012 became the number one source for recruiting; in addition, more than $90 \%$ of employers use SNS for screening purposes and $97 \%$ of recruiters use LinkedIn for hiring purposes (Hebberd, 2017). Caused by the advancement of technology HRM has seen further opportunities of growth specifically in the area of recruitment; however, employers must not expect that such advancements will solve all HR issues and will only bring them, superior employees. The digital era in the employment cycle should be incorporated with vigilance. Leading to the need to inform employers of the different aspects of the integration of the internet sites (specifically social networking sites in the current day) used in the recruiting, screening, and selecting processes. As a theory, it could be predicted that social networking sites are more valuable for recruiting than screening.

\section{Traditional Methods of Recruiting and Selecting}

Any organization incorporating social media as part of their recruiting effort should consider the overall effect it might have on the organization and the organization's hiring strategy. With the increase in global competition, organizational effectiveness is determined by its ability to attract talented personnel (Thomas \& Ray, 2000). As part of the basic acquisition of human capital, employers have to effectively accomplish the process of recruiting and selecting future employees. Recruitment and selection are complex processes in which companies search prospective employees that fit the organization's needs (Ahmad \& Schroeher, 2002). Recruiting in a simple definition is the process of attracting qualified job candidates to a company (Lussier, 2015). Selection is the process of choosing the best-qualified candidate from the pool of recruited applicants (Lussier, 2015). During the selection process, there are an assessment to determine applicants' work-related knowledge, skills and abilities (ISO 30405:2016), while also determining the hard and soft skills possessed by each job applicant (Ahmad et al., 2002).

\subsection{Description and Flaws to Traditional Methods of Recruiting}

To attract the best employees, employers must first determine their recruitment strategy and sources. Traditional recruiting sources include advertisements through newspapers and magazines, employment agencies, job fairs, and internal hiring. Recruiting through newspapers enables employers to search for applicants who already know the local community and the company. Magazines are used to recruit job applicants within specialized fields (Noe et al., 2014). However, these types of recruiting tends to attract only unskilled, skilled, or technical candidates, while professional and executives are less likely to read ads in newspapers and magazines (Fleischmann, 1993).

There are two types of employment agencies, public and private. Public employment agencies are connected with 
the Social Security Act of 1935, which require any individual seeking unemployment compensation to be registered with a public employment agency (Noe et al., 2014). Public agencies find suitable employees to fit organizations needs for a small cost while helping organizations meet diversity goals (Noe et al., 2014). Private agencies are mainly concerned with helping the organization acquire white-collar employees, and these agencies charge employers a higher fee. Such agencies are also referred to as executive search firms or "headhunters" because they concentrate on finding currently employed individuals a better-suited job with higher pay (Noe et al., 2014). Both public and private agencies strive to provide employers with the best-qualified employees while eliminating the burden of finding and interviewing job applicants. Nonetheless, agencies are only concerned with helping companies fill vacancies; thus, even providing companies with unsuitable employees, just to collect the fees (Will using a recruitment agency cost me money, n.d). In the future, this could even damage agencies' reputation.

Job fairs are also part of traditional recruitment methods used by employers. Job fairs are events where several recruiters gather for a short amount of time to meet with possible job applicants (Fleischmann, 1993). Recruiters often explore colleges and universities to acquire excellent job candidates, due to the low cost required to get participants, and the convenience that it allows for one-on-one dialogue between employers and possible applicants (Fleischmann, 1993). The limitations of job fairs include the low ratio of skilled candidates (this to actual students attending job fairs), the expectancy of job opportunity being available in the area, and the time frame of job fairs which usually take place during a strict time frame (Fleischmann, 1993). Other forms of recruiting include internal recruiting which involves filling job vacancies with employees already working for the organization (Lussier, 2015). This is done through internal job posting by which companies communicate information of a job vacancy within an organization; information is usually posted on bulletin boards, employee publications, or areas where organizations communicate with employees (Noe et al., 2014).

\subsection{Description of the Selecting Process}

The selection process is the system employers use to determine the best-suited candidate for a job position based on a series of screening processes (Landers \& Schmidt, 2016). Screening is the procedure of reviewing applicants' strengths and weaknesses, in order to make an adequate selection decision (Berryman-Fink \& Fink, 1996). The traditional screening process focuses on a person- job fit (person and organization fit) defined as the knowledge, skills, and abilities (better known as KSAs) of a job applicant that enhance the possibilities of adequately performing a job (Adkins, Russell, \& Werbel, 1994). The method used in selecting applicants varies depending on the job and each organization's culture.

In practice, the selection process starts with a review or screening of the information presented on a resume and focusing on the aesthetic form of the resume including legibility, professionalism, and grammatical and spelling errors. The screening process continues with a search for inconsistent information, irregular employment history, and additional clues that might indicate a certain applicant is well suited for the job opening (Berryman-Fink et al., 1996). After the resume screening, top candidates are then selected for an interview. Some organizations also use standardized tests during the selection process. Even though they should not be used as a sole screening device, they can provide objective information about the job candidate (Berryman-Fink et al., 1996). The validity of personality tests is still inconclusive (Youngman, 2017). According to Youngman (2017), they should be used with caution; it is recommended for employers to administer a test that has been validated with the procedures indicated by the Equal Employment Opportunity Commission. Furthermore, any standardized tests used must be relevant to job qualification, administered, and recorded consistently for all job candidates (Berryman-Fink et al., 1996).

These are just some of the most common traditional procedures used in the recruiting, screening and selecting process. Employers (HR) should adapt this process to their specific needs either organization or job wise. While traditional methods of hiring have been successful for many years, they also have various limitations that could lead employers to explore additional methods. For instance, time to announce a job vacancy with traditional methods takes time; however, by using a Web-based platform to recruit an employer can let hundreds of possible applicants instantly know about a vacancy (Zusman \& Landis, 2002); thus, leading the process of hiring to become for efficient. Furthermore, some traditional methods neglect to consider applicants time availability. When job opportunities are posting on the Web, applicants are able to gain knowledge of jobs and apply on their own time (Zusman \& Landis, 2002).

\section{Social Networking Sites (SNS)}

Even though the words "social media" and "social networking sites" are used interchangeably, they each have a specific meaning. Social media is powered by Web 2.0 allowing the interactions among individuals through 
technological devices; thus social networking sites, social shopping, social playing, and social locationing are all a component of social media (Haag \& Cummings, 2013). Social networking sites (SNS) are platforms in which individuals can automatically create an account, acquire friends, and share information (Haag \& Cummings, 2013). Social media accounts are very common and organizations are using them as a form of advertising. It has been estimated that as of 2013, U.S. companies paid over $\$ 5$ billion for social media advertisements, and by 2018 , that number was predicted to increase up to $\$ 15$ billion (Zhu, Y, \& Chen, 2015). The first social media site was launched in 1997 with the creation of Sixdegrees.com that allowed users to have a personalized online profile and a list of friends (Boyd et al., 2008). Over the years, many types of social networking sites have been launched, and as of today, some of the most popular are Facebook, Twitter, and LinkedIn in terms of hiring tools.

\subsection{Facebook}

In 2004, Facebook was launched with the main purpose of providing a contact method between students at Harvard University. Due to Facebook's incredible success, in September 2006 it transitioned into a public social media site. Such evolution made Facebook available to anyone above 13 years of age, allowing it to reach 100 million users by 2008 (Brugger, 2015). So boundless was the popularity of Facebook that 2015 one in six individuals had a Facebook account (Melanthiou, Pavlou, \& Constantinou, 2015). Many users say that Facebook has become part of their everyday activities and daily routine (Lampe, Ellison, \& Steinfield, 2008). Furthermore, as of 2017, Facebook reached two billion users making it the largest social network site in the world (Chaykowski, 2017). In reference to hiring, Facebook is a popular platform for job candidates, having a $67 \%$ of usage compared to Twitter with only $35 \%$, while having an $83 \%$ of active candidate users (Talent Works, 2017).

\subsection{Twitter}

Another distinguished social media site is Twitter, which was launched in 2006. Twitter is considered a microblogging service characterized by having a 140-character limit. Blogs are defined as websites where authors can share ideas and mostly opinionated information to their readers (Kwak, Lee, Park, \& Moon, 2010). Twitter has become famous for its "tweets" which are simply messages produced by each user, and retweets (RT) which is the process of sharing the original tweet among other users (Kwak et al., 2010). Nielson Company reported a $1448 \%$ user growth rate from 2008 to 2009 (as cited in Marwick \& Boyd, 2010). As of 2017, Twitter had over 320 million active users (Srinivasan, Senthilraja, \& Iniya, 2017). Twitter has broken the barriers for blogs and has enabled the connection of millions of peoples all around the globe while forming its own brand. According to a study done on Fortune 500 companies, $60 \%$ of job candidates use Twitter; more than $70 \%$ use it to research openings in companies and 58\% to follow companies (Westfall, n.d.).

\subsection{LinkedIn}

LinkedIn was launched in 2003, with the main idea to help build professional relations (Zide, Elman, \& Shahani-Denning, 2014). It was created with the promise of allowing professionals to be successful by providing a method to obtain jobs, meet new people, grow personal networks, and allow users to gain access to updates related to job fields or occupations. LinkedIn differs from other social media sites by having profiles that resemble the users' cover letters and resumes, and not just providing information about users' hobbies or interests. As of 2017, it had become the most used social media tool by recruiters. According to LinkedIn's website (About LinkedIn, 2017), two new members joined every two seconds throughout 200 countries (Zide et al., 2014). More than two million organizations had their own LinkedIn page, and more than 170 million professionals have an open account as of 2012 (Breitbarth, 2012). Open account refers to a social page that was created and used by an individual or company (Breitbarth, 2012). According to LinkedIn (2018), more than 550 million people are LinkedIn users. In terms of recruiting, $87 \%$ of recruiters use LinkedIn compared to 55\% pertaining to Facebook (Talent Works, 2017). The extensive number of members and its professional affiliation has allowed LinkedIn to become the most used social media site by professionals who are job hunting and organizations with job openings.

\section{Integration of SNS in the Recruiting and Selecting Process}

For many years, employers have used sites such as Careerbuilder.com in their recruiting practice, which has led to the attraction of job seekers from more than 100 career sources (Yoon Kin Tong \& Sivanand, 2005). According to Nessler (2014), Careerbuiler.com has enabled the reduction of per hire cost by $70 \%$ due to a decrease of travel costs and has also reduced by $60 \%$ the time it takes for employers to hire an employee. Electronic recruiting is the combination of the Web with the process of recruiting human capital (Melanthiou, Pavlou, \& Constantinou, 2015). Companies now have their own social media pages for recruiting job applicants (Melanthiou et al., 2015). For instance, companies are now creating their own Facebook page and using it as an advertisement tool to help attract talent (Andrews, 2012). There has also been an increase in Facebook usage by human resource professionals with the intention of finding "detailed information about job applicants," and to screen and select the best-suited 
applicants (Brown \& Vaughn, 2011, p. 219). According to Facebook, a new feature is in the works that would allow direct job postings (Take the Work out of Hiring, 2017). Furthermore, according to Facebook's official webpage job posts are now linked to the Facebook Business Page. Now job seekers can see new jobs available through the Jobs bookmarks on Facebook or on the Marketplace (Job posting on Facebook, n.d.). SNS serve as a lead to redirect followers to companies' personal website where they can learn about job vacancies (Spellmann, 2018). With such a considerable number of account holders, recruiting through Facebook gives employers a much wider variety of opportunities and challenges.

Research has established that Facebook and LinkedIn are the most popular social media recruiting sites (Melanthiou et al., 2015). According to a study conducted by the Society of Human Resource Management Survey of $541 \mathrm{HR}$ specialists, 95\% admitted to using LinkedIn as a recruiting tool; while $58 \%$ said they used Facebook, and $42 \%$ said they used Twitter (Zide et al., 2014). A survey administered to HR managers to identify what type of technology they were using in their department and for what reason, concluded that in North America technology was becoming more prevalent for the use of recruiting and selecting job applicants especially mid-level staffing. Furthermore, interviewers reported a higher quantity of applicants, but the quality seemed to remain unchanged or even lower (Chapman et al., 2003). The use of SNS for hiring varies in different countries depending on the availability of internet connection and the usage of social media. For instance, $89 \%$ of the U.S. has access to the internet, 91\% in Canada, 71\% in China, 67\% in Mexico, 39\% in Kenya, and 25\% in India (Pew Research Center, 2018). In addition, according to Pew Research Center (2018), wealthier counties such as U.S., Netherlands, Germany, Sweden, Australia, and Canada have a higher use of internet compared to developing countries such as India, Tanzania, Indonesia, and Kenya. Social media usage varies in different counties, for instance, U.S (69\%), Canada (68\%), and Russia (66\%) have higher usage compared to India (20\%), Kenya (30\%), and Indonesia (26\%) (Pew Research Center, 2018). However, developing counties are seeing an increase in the use of internet and social media from 42\% in 2013 to 64\% in 2018 ( regarding internet usage) and 34\% from 2013 to 53\% in 2018 (regarding SNS usage) (Pew Research Center, 2018). Taking those numbers into consideration the integration of SNS in the hiring process is more likely to occur in developed counties.

\section{Advantages, Risks, and Other Consideration of SNS in the Hiring Process}

Without a doubt, there are advantages to using SNS in the hiring process. Many organizations have already incorporated it to some degree. Some examples of SNS benefits include (1) reduced cost and reduced time-to-hire, (2) the ability to reach out to a younger generation and a larger number of applicants, (3) attracting passive job applicants, and (4) providing employers with a different tool to predict the performance of a future employee. Nevertheless, there are several challenges associated with this topic, which must be addressed. The main challenges include (1) legal issues, (2) the inability to recruit a diverse pool of candidates (in regards of age, gender, and race), and (3) the lack of validity and reliability of these platforms. As a hiring strategy, SNS provide more advantages in the recruitment phase, since there is no harm in attracting more job applicants when the cost is minimal. From a general perspective, SNS may cause more problems if used during the screening and selection phase. Lastly, employers may fail to consider challenges placed by SNS when matching candidate experience and employer brand.

\subsection{The Use of SNS Reduces both Cost and Time While Being Equally Effective}

The cost of recruiting talent increased by seven percent in just one year from 2014 to 2015, this based on a study of 412 United States companies, leading to a cost of almost $\$ 4000$ per hired applicant (Phillips-Wren, Doran, \& Merrill, 2016). Other research claims that traditional recruiting methods cost employers an average of $\$ 3,295$ while using "web-based" recruiting can cut the cost down to only $\$ 377$ (Broughton, Foley, Lendermaier, \& Cox, 2013). In addition, Innovex reported a reduction of screening cost cut by half while using information technology (Chapman et al., 2003). Social media recruiting is one of the less expensive ways of recruiting since companies can post a job vacancy announcement free on their social page, or pay a minimum amount to use online recruitment sites (Melanthiou, Pavlou, \& Constantinou, 2016). Social networking sites are helping recruiters become more cost-conscious by relying on SNS to recruit a global pool of applicants in contrast to recruiting only those in the local area (Gibbs, MacDonald, \& MacKay, 2015).

Cost saving can be associated with the use of social media as long as recruiters know how to use it. Recruiting costs can be saved with social media by avoiding third-party recruiting fees (Leader-Chivee \& Cowan, 2008). For large corporations seeking to attract international candidates, the cost associated with third-party recruiting could be very high. For such reason, many are discouraged from recruiting internationally. The use of technology and social media sites also tends to reduce the costs associated with transportation, hotels, meals, and other expenses; while also expanding the pool of applicants (Chapman et al., 2003). Cost reduction is a seductive advantage for 
those looking for less expensive ways to hire employees since the cost of hiring new employees is increasing every year.

After the 2008 recession, industries were obligated to cut budgets, and as a result, resorted to social media sites as a form of advertising. According to a survey conducted by MarketingSherpa's Social Media Marketing, of firms' online marketing budget, $11 \%$ was allocated to social media (as cited in Kirtis \& Karahan, 2011). Another survey done by DEI Worldwide in 2008, found that social media websites were preferred as a method to pass along information (as cited in Kirtis \& Karahan, 2011). According to ROI measurements published by SHRM, Novartis filled 40 job vacancies using social media at a $20 \%$ faster rate while also increasing the diversity of the candidates (Babcock, 2010). In a specific example, RS Components took advantage of social media to engage with potential job candidates and current employees. Through the process, they found the strategy to be cost effective and time-saving. During the time span of 12 months, they were able to fill 35 job openings while also reducing the time needed to identify candidates from seven to four hours (Hull, 2011).

\subsection{The Use of SNS Helps Organizations Reach the Younger Generations Such as Millennials}

With the retirement of Baby Boomers, businesses are striving to replace them with the next generations, such a millennials. Millennials (also known as Generation Y), have grown up with technology as a component of their everyday routine. Millennials are those individuals born during the 20th century and range in age from their early 20 s to early 30s (Weiner, 2016). Of this generation, around $92 \%$ use social media (Gibbs et al., 2015). The advantage of social media in the recruiting process is the undeniable appeal to current college students, who are considered millennials (Goodmon, Smith, Ivancevich, \& Lundberg, 2014). In addition, the new generations like to think of their employers as "friends," and social media allow this kind of interaction (Goodmon et al., 2014). Employers are interested in reaching out to millennials and hearing about their interests, and they have found social media sites are an incredible way to meet this need (Phillips-Wren et al., 2016). Millennials, in comparison, value perspective employers communicating with them through social media (Phillips-Wren et al., 2016).

Statistics demonstrate that $73 \%$ of millennials "obtained their last job through a social media platform" (Weiner, 2016, p. 28). Twitter has influenced the popularity of hashtags, which has simplified the process of finding a specific job-related opening (Weiner, 2016). Facebook, for instance, allows employers to recruit for specific demographics (Spellmann, 2018). Millennials, more than any other older generation, rely on social networking sites for employment reason, and generations that follow will likely continue this trend (Broughton et al., 2013). In addition, the use of social media gives employers a pool of diverse candidates since they are reaching out to a more diverse, worldwide audience (Broughton et al., 2013). This could lead to a more diverse range of employees.

\subsection{The Use of SNS Helps Organizations Reach Passive Candidates, Thus Expanding the Overall Candidate Pool}

There are two types of job seekers, active and passive. They are similar in the context of having adequate skills and abilities, but they are at a different point in the employment cycle (Cohen, 2009). Active job seekers are those job-hunting, they typically apply directly for a position. Most of the time they already know the company to which they apply and are eager to start working. On the contrary, passive candidates are harder for employers to find since they tend to be employed and satisfied with their current position, and are not interested in seeking other employment opportunities (Cohen, 2009). These candidates are highly talented and possess job experience since they may have been working for the same employer for years (Doherty, 2010). They are desirable to employers because they are stable and usually experienced employees (DeKay, 2009).

Having explained the difference between active and passive candidates, how does social media affect passive candidates? In theory, SNS is becoming an essential tool that allows employers to interact and communicate with passive candidates (Doherty, 2010). Currently, passive candidates can be reached with an advertisement of job vacancies through social media websites. It is predicted that in the future HR will be able to target passive job candidates through social platforms by keeping track with them by building a more personalized relationship (Doherty, 2010). Passive job candidates can mostly be found by employers on personal-oriented sites such as Facebook and Twitter (Nikolaou, 2014). Nevertheless, research has found that passive job seekers still maintain a LinkedIn profile on which they maintain a professional image, but are less likely to respond to job opening compared to active candidates (Nikolaou, 2014). Therefore, the opportunity of using SNS to hire passive candidates could lead to a larger, more experienced pool of candidates.

\subsection{The Use of SNS Allows Employers to Predict Job Performance}

Many employers conduct employee screening using various testing methods in order to predict prospective employees' job performance. For many years personality tests like the Big Five personality traits test, which measures the levels of extraversion, agreeableness, neuroticism, openness to experience, and conscientiousness, 
have been used as job performance predictors (Goodmon et al., 2014). In contrast, experts suggest that social networking sites like Facebook provide better insight to employers about possible employees' performance over that of personality tests (Goodmon et al., 2014). There has also been a comparison of the use of social media and the neurotic and extraversion characteristic of employees, which give similar results (Regts \& Mollenman, 2016). Social media and personality tests can both predict future employees' performance because they are a reflection of the unconsciousness of the employee (Regts et al., 2016). In contrast, these results can be inaccurate because applicants can always fake information, such as showing extraversion characteristics online while lacking them in real life (Regts et al., 2016).

Employers seeking to understand a candidate via social media should focus on the knowledge, skills, and abilities (KSAs) portrayed on such platforms. The goal is to predict a job-fit with a potential employee (Roth, Bobko, Iddekinge, \& Thatcher, 2013). It is recommended for employers implementing this strategy to weigh predictions made from social media information against software programs in order to prove validation (Roth et al., 2013). Other recommendations include concentrating on information found on professional social sites such as LinkedIn, and "ways to structure interviews that could be adapted for SM assessment" (Roth et al., 2013 p. 24).

\subsection{The Use of SNS Can Affect Employers in a Legal Matter if They Are not Cautious}

First, it is important to mention the implications of Equal Employment Opportunity (EEO), which regulates how human resource processes are conducted. EEO states that all individuals seeking a job must have an equal opportunity to be employed regardless of their race, color, religion, sex, age, disability, and national origin (Noe et al., 2014; Title VII of the Civil Rights Act of 1964). The main purpose of Title VII is the prohibition of discrimination based on race, color, religion, sex, or national origin in the employment process (Noe et al 2014., Title VII of the Civil Rights Act of 1964). While hiring, the human resource department should make sure no law is being violated, even when they are using SNS for the purpose of recruiting and selecting employees.

One legal concern is the accuracy of information found on SNS. If an applicant is not hired based on incorrect information found on their social platforms they could have a legal case, arguing "defamation of character" (Broughton et al., 2013). In 2011, a Society for Human Resource Management study concluded that $48 \%$ of organizations that reported not using social media screening gave the reason of the failure to validate information found (Gibbs et al., 2015). Legal privacy is most likely to be based on the "job-relevance of the information obtained" (Broughton et al. 2013, p. 30). In addition to legal risks, companies should keep in mind their image and applicants' reactions to the "real or perceived invasion of privacy" (Broughton et al., 2013, p. 30). Furthermore, other legal issues include possible discrimination while using social media. Any information regarding race, gender, sex, age, religion, or disability acquired through social media and that is used as a basis of not hiring or hiring is considered illegal (Melanthiou et al., 2015). If the employer tends to know "too much" about job applicants, they could use that information as a source of discrimination (Broughton et al., 2013).

While keeping legal issues in mind, employers could adversely encounter a lawsuit related to a negligent hiring decision. Negligent hiring occurs when an employer hires an employee who causes harm to another person, while this situation could have been avoided if the employer took the time to correctly screen that employee (Bennett-Alexander \& Harman, 2015). Consequently, through the screening of applicants' SNS, employers could refuse to hire an applicant depending on the information found. For instance, if inappropriate or provocative content was found, information about drugs, negative language about the previous employer, proof of poor communication skills, discriminatory comments, lies about qualifications, and disclosure of previous employer's confidential information could lead an employer to refuse to hire an applicant (Bennet-Alexander \& Harman, 2015).

When incorporating any processes into a business setting that affects employees, in general, there will also be the debate on the legality of such method and how to avoid problems. According to the former president of the American Bar Association, Steve Zack, seeking counseling in legal matters related to technology is more effective than hiring a lawyer during a problem (Seeds, 2011). In terms of screening social media, employers should delegate that job to a low-level member; this person should not be involved in the hiring decision (Seeds, 2011). According to the Society for Human Resource Management solutions to avoid legal problems while using SNS are never asking for passwords in order to not violate the Stored Communications Act, have HR involved in screening, check social media further in the hiring process, have a consistent method, and consider sources and document decisions for hiring or rejecting (Segal, 2018). Overall the main recommendation to avoid legal actions is for the HR department or the employers is to have "well-documented evidence for validity" of all information used in the hiring process of every job applicant (Broughton et al., 2013, p. 32). SNS information should merely reinforce initial decisions established through information presented in cover letters, resumes, and interviews (Ross et al., 
2012). The legal cost of inadequate use of social media could possibly be more than the money saved in the recruitment through these platforms. While using social media organizations should keep a balance in order to avoid legal actions and keep informed of any new laws regarding the hiring process and social media.

\subsection{SNS Fail to Provide Employers with Diverse Job Candidates}

Even though social media recruiting can generate a larger diversity pool because it reaches out globally, it concentrates on a narrow group of possible applicants. For example, social media sites are commonly used by younger generations like millennials (Broughton et al., 2013). Other generations like Generation X and Baby Boomers may still prefer traditional employment methods. If companies focus mainly on social media recruiting they could be violating civil right laws if they are not hiring employees over 40 years of age since they are less likely to use social media as a method to find a job (Broughton et al., 2013). Even though of Generation X, 80\% have a Facebook or Twitter they tend to neglect being active; while of those over 65 years, only $45 \%$ have an SNS (Bose, 2017). Others less likely to use social media are those of low income or of a certain racial or ethnic group (Broughton et al., 2013). When using social recruiting the applicant pool is more likely to be made of young, highly educated, white males; who are frequent job changes (job-hoppers) (Broughton et al., 2013). The concern for diversity can be a great influencer for organizations that want to depend solely on this type of recruitment process.

The digital divide can also play an important factor in terms of diverse candidates. Digital divide refers to disparity among those who have access to personal computers and internet service and those who do not (Samuel \& Nyarko, 2014). This disparity can be between those of high income and low-income (including minorities or unemployed) (Samuel \& Nyarko, 2014). Those unemployed are up to 73\% less likely to have constant access to the Internet (Yu, Ellison, McCammon \& Langa, 2015). The increase in education increases the probability of access to the Internet by $33 \%$ and increases in income increase possibilities by $29 \%$ (Yu et al., 2015). This problem can limit the number of individuals who can be reached through electronic recruitment. For instance, only $47 \%$ of Blacks and $45 \%$ of Hispanics have access to the Internet compared to the White population (Yu et al., 2015). Samuel and Nyarko (2014) concluded that any type of e-recruitment should solely serve as a supplement to traditional recruitment. Not all groups are equally present on SNS leading to inequality (Jeske \& Shultz, 2016). Other issues affecting the digital divide is the actual motivation of individuals to take advantage of information found through the web (Yu et al., 2015). Lastly, it was concluded that with age the availability or desire to have access to the internet decreases by $8 \%$ (Yu et al., 2015).

\subsection{The Use of SNS for Recruitment and Selecting Lacks Reliability and Validity}

Another challenge faced by SNS is the inability to prove its reliability and validity. Reliability is defined as the degree to which results are consistent, stable, and accurate over a period of time (Golafshani, 2003). Validity, in contrast, consists of evidence, objectivity, truth, facts, and actuality. Validity is the concept that determines whether research measures the object to which it was created to measure and how truthful the results are (Golafshani, 2003).

In Hong Kong, Robert Half conducted research on LinkedIn's reliability on 150 financial officers questioning them about the reliability of LinkedIn. Of those surveyed two-thirds stated that information presented on profiles was occasionally reliable, and seven percent said they never trusted LinkedIn profiles (Asset Services, 2013). With the reliability of the users of LinkedIn being poorly rated, the possibility of attracting suitable candidates decreases in the eyes of employers. In reference to reliability and validity, there is not enough documentation or research on how SNS information correlates to employees in the workforce (Jeske et al., 2016). Thus, future research on this topic is required. This topic ties to the selection method of the hiring process. As such, the issue of reliability and validity play a crucial role when it comes to screening applicants' social media sites. The question in term is, are the profiles of job candidates and the information presented accurate and trustworthy? In addition, it is believed that the information retrieved lacks interpretability since it is information based on behaviors (Landers \& Schmidt, 2016). When employers make judgments based on SNS information they may be overlooking relevant information and making judgments based on personalities (Landers \& Schmidt, 2016). Using social media as a mere form of selecting can be controversial due to the lack of actual research concerning the reliability and validity of the information presented on such platforms.

Social networking sites are important to the theory of information asymmetry; this process deals with the sharing of information through different platforms (Stefanone, Hurley, Egnoto, \& Corvet, 2015). Information asymmetry states that one party has superior information than the other party (Stefanone et al., 2015). This could be tied to SNS since through their use there is a high degree of information sharing and direct advertising. As this theory exists, it could lead to a lack of reliability in social media that could be transferred when used in the hiring process 
since one party (candidate) has real information compared to the other (employer) who just interprets it. However, no research has been conducted on this topic when using SNS for hiring. The number of profiles on Facebook, LinkedIn, and Twitter are extremely high and growing by the day. There are also many people with the same name living in the same geographical area, and employers could encounter a problem while searching for an applicant's social media site whom they have not met personally. This could lead to an error, and a qualified candidate may be rejected based on inappropriate information of another individual's social media account (Ross et al., 2012). For example, Facebook mistaken identity is common due to the easy tagging of wrong profiles (Ross et al., 2012). In addition, an employer should consider the date of the information obtained. Some profiles are not updated for years, and the information available could represent a different phase of the job applicant life, and such information could be misleading to employers (Ross et al., 2012). Finally, SNS information does not accurately reflect the behavior of an applicant as an employee. People tend to behave differently in a personal setting and in work settings. This change in behavior may be due to situational factors such as workplace norms and individual characteristics such as personality factors (Ross et al., 2012). These are some examples of how information acquired by employers could be inaccurate and could lead to an erroneous hiring or non-hiring decision.

In order for social media to be considered reliable, the Standards of Educational and Psychology Testing should accredit it with the certifying body of the National Institute for Social Media (NISM). NISM seeks certification for the National Commission of Certifying Agencies, in addition, to collaborating with Paradigm Testing, which is connected with Social Media Strategist (NISM, n.d.). When adding SNS to the hiring process employers must take into consideration the stance of each company, the adequacy could be determined by the attitudes, needs, and preference of management.

\subsection{Job Applicants' Use of SNS to Express Candidate Experience Directly Affects Employers Brand Image}

Even though brand image and candidate experience cannot be easily classified as an advantage or challenge of SNS, it is still worth mentioning due to the impact it has on how job seekers and employers use SNS for mutual benefits. Candidate experience is one of the key procedures involved in the hiring process. Candidate experience is defined by Crispin \& Mehler, as the individuals' views about a certain business's overall processes (as cited in Headworth, 2015).

According to Hughes, director of Monster Professional Services, this involves not only how recruiters are treating job candidates, but most importantly how candidates feel they are being treated (Improving the Candidate Experience Monster.com, n.d.). This in return can translate as a positive or negative experience for a job candidate. Social media platforms such as Facebook and Twitter serve as a gateway for candidates to pass on to others their experience with a certain company either positive or negative. Specific websites such as Glassdoor provides job candidates with the pros and cons of working for a specific company (Headworth, 2015).

The image an employer portrays to its employees and job applicants can affect the overall brand image, and as a result, either benefits or hurt them when it comes to attraction and retention of employees (Headworth, 2015). Those seeking employment in certain companies learn from "insider's viewpoints" while investigating organizations social media pages (Phillips-Wren et al., 2016). In addition, in 2010, Talent Board created a comparison benchmark that focused on candidate experience based on principles of recruitment. This process required the direct collaboration of candidates and their essential feedback (Headworth, 2015). The studies then led to Candidate Experience Awards or also known as the CandEs. The CandEs consists of industries willing to participate, as of 2014, there were around 170 companies with over 95,000 candidates participating (Headworth, 2015). The main goal of the CandEs is to award outstanding recruiting practices, while in return those awarded shared their best practices (Headworth, 2015). One of the main findings was that $96.9 \%$ of candidates who have experienced a positive experience with an employer would recommend others to apply. On the other hand, of those candidates who have had a negative experience only $33.2 \%$ would recommend others to apply (Headworth, 2015).

In a study conducted on 184 engineering students (soon to be job seekers) concluded that candidates' perception of employers' use of SNS had a positive correlation with good corporate reputation, and a good corporate reputation had a positive correlation to candidates' intention to apply for a job (Stuart Roper \& Sivertzen, 2013). The overall conclusion of this study was that "social media may play a key role in the recruitment process in terms of branding the organization to potential employees" (Stuart Roper et al., 2013, p. 480). Six studies on e-recruiting conducted on various industries (oil and gas, retailers, real estate, and security) concluded that its participants knew about the benefits of e-recruitment especially in reference of "positive candidate experience and strong employer brand" (Allden \& Harris, 2013, p. 40). The recommendation following this research was to include philosophy of positive candidate experience as a core goal while engaging in e-recruitment strategy, (Allden et al., 2013).

A survey conducted by Jibe (State of Employer Branding Survey), on more than a hundred recruiters demonstrated 
that 95\% believed candidate experience affected employers' brand (Roberts, 2017). According to Robert (2017), the flow of information through social media can definitely influence employers' reputation nowadays. It was advised that employers should oversee all aspects of candidate experience since the brand image depends on it. The advice given to Jibe over candidate experience, by Gerry Crispin, suggests that employers should set clear exceptions, listen to candidates, demonstrate fairness, provide closure, and demand accountability (as cited in Roberts, 2017). With the availability of all types of information through different social platforms candidate experience and brand image are both affected by SNS.

\section{Summary and Conclusion}

The use of social networking sites for hiring has shifted the focus away from traditional forms of recruiting and selecting. In addition, SNS can affect the candidate experience and employer image. Social networking sites' use can be successful in recruitment if used to post job vacancies, post locations of recruitments, or to redirect applicants to companies' websites. Thus, if the result is hiring employees at a lower cost and at a faster rate than competitors a company can achieve a competitive advantage. In addition, it enables the recruitment of a younger generation and the inclusion of passive candidates. Furthermore, social media could allow employers to predict future employees' performance, and this could give them the advantage of knowing whom they are hiring. The use of social media sites for hiring possesses several pitfalls mainly concerning the screening and selecting phase. SNS are opening new areas of concern in reference to the legality of this tool for the hiring process. Are employers hiring a diverse pool of candidates while using SNS or are they simply attracting a higher amount of candidates? In reference to reliability and validity, social media tends to lack both, and employers should consider the accuracy of the information found. The overall future of social networking sites in the hiring process is still unclear due to the lack of research. Nonetheless, taking into account its present reality, the number of employers joining this trend will continue to grow, and employers need further insight into this process in order to evaluate its actual influence in the hiring process. Finally, it is worth mentioning again, that the analysis presented mainly concerns employers located in developed countries.

\section{References}

About LinkedIn. (2017). Retrieved December 05, 2017, from https://press.linkedin.com/aboutlinkedin

Adkins, C. L., Russell, C. J., \& Werbel, J. D. (1994). Judgments of fit in the selection process: the role of work value congruence. Personnel Psychology, 47(3), 605-623. https://doi.org/10.1111/j.1744-6570.1994.tb01740.x

Ahmad, S., \& Schroeder, R. G, (2002). The importance of recruitment and selection process for sustainability of total quality management, International Journal of Quality \& Reliability Management, 19(5), 540-550. https://doi.org/10.1108/02656710210427511

Allden, N., \& Harris, L. (2013). Building a positive candidate experience: towards a networked model of e-recruitment. Journal Of Business Strategy, 5, 36. https://doi.org/10.1108/JBS-11-2012-0072

Andrews, C. (2012). Social media recruitment. Applied Clinical Trials, 21(11), 32.

Asset Services: Executives are questioning the reliability of LinkedIn. (2013). Asian Investor, 1.

Babcock, P. (2010, November 22). Recruiting Strategies for Social Media. Retrieved May 22, 2018, from https://www.shrm.org/resourcesandtools/hr-topics/talentacquisition/pages/recruitingstrategiesforsocialmedia .aspx

Bennett-Alexander, D., \& Hartman, L. P. (2015). Employment law for business. New York, NY: McGraw-Hill Education.

Berryman-Fink, C., \& Fink, C. B. (1996). Recruiting and selecting new employees. In, Manager's Desk Reference (p. 269).

Bose, S. (2017, March 08). Surprising stats on every generation's social media habits (Infographic). Retrieved October 10, 2018, from https://smallbiztrends.com/2017/03/social-media-usage-by-age.html

Boyd, D. M., \& Ellison, N. B. (2008) Social network sites: Definition, history, and scholarship. Journal of Computer Mediated Communication, 13(1), 210-230. https://doi.org/10.1111/j.1083-6101.2007.00393.x

Breaugh, J. A. (2008). Employee recruitment: Current knowledge and important areas for future research. Human Resource Management Review, 18(3), 103-118. https://doi.org/10.1016/j.hrmr.2008.07.003

Breitbarth, W. (2012). The brand named: you. Quality Progress, 45(7), 22-26.

Broughton, A., Foley, B., Lendermaier, S., \& Cox, A. (2013). The use of social media in the recruitment process. 
The Institute for Employment Studies, 1-81. Retrieved from http://www.acas.org.uk/media/pdf///b/The-use-of-social-media-in-the-recruitmentprocess.pdf

Brown R., V., \& E. Vaughn, D. (2011). The writing on the (Facebook) wall: The use of social networking sites in hiring decisions. Journal of Business and Psychology, 2, 219. https://doi.org/10.1007/s10869-011-9221-x

Brügger, N. (2015). A brief history of Facebook as a media text: The development of an empty structure. First Monday, 20(5). https://doi.org/10.5210/fm.v20i5.5423

Chapman, D. S., \& Webster, J. (2003). The use of technologies in the recruiting, screening, and selection processes for job candidates. International Journal of Selection \& Assessment, 11(2/3), 113-120. https://doi.org/10.1111/1468-2389.00234

Chaykowski, K. (2017). Mark Zuckerberg: 2 billion users means facebooks 'responsibility is expanding'. Retrieved December 04, 2017, from https://www.forbes.com/sites/kathleenchaykowski/2017/06/27/facebook-officially-hits-2billion-users/\#593b 52493708

Cohen, E. (2009). Innovative recruiting- targeting passive professionals. Power Engineering, 113(10), 8-10.

Deadrick, D. L., \& Stone, D. L. (2014). Human resource management: Past, present, and future. Human Resource Management Review, 24(3), 193-195. https://doi.org/10.1016/j.hrmr.2014.03.002

DeKay, S. (2009). Are business-oriented social networking web sites useful resources for locating passive jobseekers? Results of a recent study. Business Communication Quarterly, 72(1), 101-105. https://doi.org/10.1177/1080569908330378

Doherty, R. (2010). Getting social with recruitment. Strategic HR Review, 9(6), 11-15. https://doi.org/10.1108/14754391011078063

Fleischmann, S. T. (1993). A systematic approach to effective recruitment. Employment Relations Today, 1. 69 https://doi.org/10.1002/ert.3910200110

Gibbs, C., MacDonald, F., \& MacKay, K. (2015). Social media usage in hotel human resources: recruitment, hiring and communication. International journal of contemporary hospitality management, 27(2), 170-184. https://doi.org/10.1108/IJCHM-05-2013-0194

Golafshani, N. (2003). Understanding reliability and validity in qualitative research. The Qualitative Report, 8(4), 597-606. Retrieved from http://nsuworks.nova.edu/tqr/vol8/iss4/6

Goodmon, L. B., Smith, P. L., Ivancevich, D., \& Lundberg, S. (2014). Actions speak louder than personality: effects of Facebook content on personality perceptions. North American Journal Of Psychology, 1 .

Haag, S., \& Cummings, M. (2013). Management information systems for the information age (9th ed.). New York, NY: McGraw-Hill//Irwin.

Headworth, A. (2016). Social media recruitment: How to successfully integrate social media into recruitment strategy. Philadelphia, PA: Kogan Page Stylus.

Hebberd, L. (2017, January 09). The evolution of finding candidates. Retrieved from https://theundercoverrecruiter.com/evolution-finding-candidates/

Hull, J. (2011, April 27). 50\% reduction on recruitment costs: How social media became my best friend. Retrieved May 22, 2018, from http://www.hrmagazine.co.uk/article-details/50reduction-on-recruitment-costs-how-social-media-became-m y-best-friend

Improving the Candidate Experience | Monster.com. (n.d.). Retrieved April 02, 2018, from https://hiring.monster.com/hr/hr-best-practices/small-business/archivedwebinars/monster-candidate-experie nce-webinar.aspx

ISO 30405:2016 (2016) Human resource management- guidelines on recruitment, $1^{\text {st }}$ ed. Technical Committee/Subcommittee TC 260/WG5; ISO Standards.

Jeske, D., \& Shultz, K. S. (2016). Using social media content for screening in recruitment and selection: pros and cons. Work, Employment \& Society, 30(3), 535-546. https://doi.org/10.1177/0950017015613746

Job postings on Facebook. (n.d.). Retrieved March 26, 2018, from https://www.facebook.com/business/learn/facebook-page-post-jobs 
Kaufman, B. E. (2014). The historical development of American HRM broadly viewed. Human Resource Management Review, 24(3), 196-218. https://doi.org/10.1016/j.hrmr.2014.03.003

Kirtiş, A. K., \& Karahan, F. (2011). To be or not to be in social media arena as the most cost-efficient marketing strategy after the global recession. Procedia - Social and Behavioral Sciences, 24, 260-268. https://doi.org/10.1016/j.sbspro.2011.09.083

Kwak, H., Lee, C., Park, H., \& Moon, S. (2010). What is twitter, a social network or a news media? Association for Computing Machinery, 591-600. https://doi.org/10.1145/1772690.1772751

Lampe, C., Ellison, N. B., \& Steinfield, C. (2008). Changes in use and perception of Facebook. Association for Computing Machinery, 721-730. https://doi.org/10.1145/1460563.1460675

Landers, R. N., \& Schmidt, G. J. (2016). Social media in employee selection and recruitment: Theory, practice, and current challenges. Switzerland: Springer. https://doi.org/10.1007/978-3-319-29989-1

Leader-Chivée, L., \& Cowan, E. (2008). Networking the way to success: Online social networks for workplace and competitive advantage. People \& Strategy. pp. 40-46.

Lussier, R. N. (2015). Management fundamentals: concepts, applications, \& skill development (7th ed.). Los Angeles, CA: SAGE.

Marwick, A. E., \& Boyd, D. (2010). I tweet honestly, I tweet passionately: Twitter users, context collapse, and the imagined audience. New Media \& Society, 13(1), 114-133. https://doi.org/10.1177/1461444810365313

Melanthiou, Y., Pavlou, F., \& Constantinou, E. (2015). The use of social network sites as an erecruitment tool. Journal of Transnational Management, 20(1), 31-49. https://doi.org/10.1080/15475778.2015.998141

Nessler, M. (2014). Three ways virtual technologies are making a difference in hr. Employment Relations Today, 40, 47-52. https://doi.org/10.1002/ert.21433

Nikolaou, I. (2014). Social networking web sites in job search and employee recruitment. International Journal of Selection and Assessment, 22(2), 179-189. https://doi.org/10.1111/ijsa.12067

NISM. (n.d.). Standards and Accreditation. Retrieved January 19, 2019, from https://nismonline.org/about-nism/standards-and-accreditation/

Noe, R. A., Hollenbeck, J. R., Gerhart, B., \& Wright, P. M. (2014). Fundamentals of human resource management (5th ed.). New York, NY: McGraw-Hill Education.

Pew Research Center. (2018, June 14). Social media use continues to rise in developing counties but plateaus across developed ones. Retrieved January 10, 2019, from http://www.pewglobal.org/2018/06/19/social-media-use-continues-to-rise-in-developing-countries-but-plate aus-across-developed-ones/pg_2018-06-19_global-tech_0-04/

Phillips-Wren, G., Doran, R., \& Merrill, K. (2016). Creating a value proposition with a social media strategy for talent acquisition. Journal of Decision Systems, 25(Supp1), 450-462.

https://doi.org/10.1080/12460125.2016.1187398

Regts, G., \& Molleman, E. (2016). The moderating influence of personality on individual outcomes of social networks. Journal of Occupational \& Organizational Psychology, 89(3), 656-682. ttps://doi.org/10.1111/joop.12147

Roberts, M. (2017, January 4). How candidate experience impacts your employer brand. Retrieved June 26, 2018, from https://www.jibe.com/ddr/candidate-experience-employerbrand-relationship/

Ross, S., \& William H., R. (2012). Should human resource managers use social media to screen job applicants? Managerial and legal issues in the USA. Info, 1, 55.

Roth, P. L., Bobko, P., Iddekinge, C. H., \& Thatcher, J. B. (2013). Social media in employee-selection-related decisions. Journal of Management, 42(1), 269-298. https://doi.org/10.1177/0149206313503018

Samuel, O. A., \& Nyarko, K. S. (2014). Leveraging information technology (IT) in recruitment and selection processes- a comparative study. International Journal of Network and Communication Research, 2(1), 16-44. Retrieved from http://www.eajournals.org/wpcontent/uploads/Leveraging-Information-Technology-It-In-Recruitment-and-S election-Processes-A-Comparative-Study.pdf

Seeds, D. (2011). Are you doing what it takes to avoid costly litigation? Smart Business Akron/Canton, 21(5), 14-17. Retrieved from 
https://zeus.tarleton.edu/login?url=https://search-ebscohost-com.zeus.tarleton.edu/login.aspx?direct=true\&d $\mathrm{b}=\mathrm{bth} \& \mathrm{AN}=66934570 \&$ site $=$ eds-live

Segal, J. A. (2018, April 11). Legal trends social media use in hiring: Assessing the Risks. Retrieved January 19, 2019, from https://www.shrm.org/hr-today/news/hr-magazine/Pages/0914-social-media-hiring.aspx

Spellmann, E. (2018, September 14). How to leverage social media to benefit your business. Seminar presented at Ranger College Erath County, Stephenville, TX.

Srinivasan, R., Senthilraja, M., Iniyan, S., (2017). Pattern recognition of Twitter users using semantic topic modelling. (2017). 2017 International Conference on IoT and Application (ICIOT), IoT and Application (ICIOT), 2017 International Conference on, 1. https://doi.org/10.1109/ICIOTA.2017.8073636

Stefanone, M. A., Hurley, C. M., Egnoto, M. J., \& Covert J. M. (2015) Information asymmetry and social exchange: exploring compliance gaining online, Information, Communication \& Society, 18(4), 376-389, https://doi.org/10.1080/1369118X.2014.952658

Stuart Roper, D. D., \& Sivertzen, A. (2013). Employer branding: employer attractiveness and the use of social media. Journal Of Product \& Brand Management, 1(7), 473.

Take the Work Out of Hiring. (2017, February 15). Retrieved March 10, 2018, from https://www.facebook.com/business/news/take-the-work-out-of-hiring

Talent Works. (2017). 8 social media statistics you need to know if you're in recruitment-infographic. Retrieved January 10, 2019, from https://www.talent-works.com/2017/09/27/social-media-recruitment/

Thomas, S. L., \& Ray, K. (2000). Recruiting and the web: high-tech hiring. Business Horizons, 43(3), 43-52. https://doi.org/10.1016/S0007-6813(00)89200-9

Title VII of the Civil Rights Act of 1964. (n.d.). Retrieved August 29, 2018, from https://www.eeoc.gov/laws/statutes/titlevii.cfm

Weiner, W. (2016). The influence of social media on job seekers in the digital age. Career Planning \& Adult Development Journal, 32(3), 26-31.

Westfall, B. (n.d.). How Fortune 500 Companies Engage Talent on Twitter. Retrieved January 10, 2019, from https://www.softwareadvice.com/resources/how-fortune-500-companies-engage-talent-on-twitter-update/

White, D. (2018, April 9). Personal interview.

Will using a recruitment agency cost me money? (n.d.). Retrieved August 28, 2018, from https://worksmart.org.uk/careers-advice/finding-job/recruitment-agencies/will-usingrecruitment-agency-cos t-me-money

Youngman, J. F. (2017). The use and abuse of pre-employment personality tests. Business Horizons, 60(3), 261-269. https://doi.org/10.1016/j.bushor.2016.11.010

Yu, R. P., Ellison, N. B., Mccammon, R. J., \& Langa, K. M. (2015). Mapping the two levels of digital divide: Internet access and social network site adoption among older adults in the USA. Information, Communication \& Society, 19(10), 1445-1464. https://doi.org/10.1080/1369118X.2015.1109695

Zhu, Y., \& Chen, H. (2015). Social media and human need satisfaction: Implications for social media marketing. Business Horizons, 58(3), 335-345. https://doi.org/10.1016/j.bushor.2015.01.006

Zide, J., Elman, B., \& Shahani-Denning, C. (2014). LinkedIn and recruitment: how profiles differ across occupations. Employee Relations, 36(5), 583-604. https://doi.org/10.1108/ER-07-2013-0086

Zusman, R., \& Landis, R. (2002). Applicant preferences for Web-based versus traditional job postings. Computers in Human Behavior, 18(3), 285-296. https://doi.org/10.1016/S0747-5632(01)00046-2

\section{Copyrights}

Copyright for this article is retained by the author(s), with first publication rights granted to the journal.

This is an open-access article distributed under the terms and conditions of the Creative Commons Attribution license (http://creativecommons.org/licenses/by/4.0/). 